\title{
Slip Effect on MHD Chemically Reacting Convictive Boundary Layer Flow with Heat Absorption
}

\author{
Mekonnen Shifferaw Ayano ${ }^{1}$ and Negussie Tadege Demeke ${ }^{2}$ \\ ${ }^{1}$ Department of Mathematics, University of Swaziland, P. Bag 4, Kwaluseni M201, Swaziland \\ ${ }^{2}$ Mechanical Engineering Department, Arba Minch University, B.O. Box 21, Arba Minch, Ethiopia \\ Correspondence should be addressed to Mekonnen Shifferaw Ayano; mekk_aya@yahoo.com
}

Received 16 November 2015; Accepted 20 March 2016

Academic Editor: Junling Hu

Copyright (c) 2016 M. S. Ayano and N. T. Demeke. This is an open access article distributed under the Creative Commons Attribution License, which permits unrestricted use, distribution, and reproduction in any medium, provided the original work is properly cited.

\begin{abstract}
The aim of this paper is to investigate steady magneto micropolar fluid past a stretched semi-infinite vertical and permeable surface taking into account heat absorption, hall and ion-slip effect, first-order chemical reaction, and radiation effects. The system of coupled nonlinear equations is solved numerically and the effects of various parameters on the velocity, the microrotation, the temperature, and the concentration field are calculated. The following discovery was made: an increase in the hall parameter strongly enhances the fluid velocity, an increase in the heat absorption parameter increases the temperature, and an increase in the slip parameter decreases the velocity. Additionally, the local skin friction, Nusselt number, and Sherwood number are also analyzed for various parameters and presented in table form.
\end{abstract}

\section{Introduction}

The micropolar fluids are non-Newtonian fluids with microstructures such as polymeric additives, colloidal suspensions, and liquid crystals. Erigen $[1,2]$ first developed the theory of micropolar fluids and thermomicropolar fluids to describe such characteristics. A thorough review of the subject and applications of micropolar fluid mechanics was provided by Ariman et al. [3, 4]. These fluids are realistic and important from a technological point of view.

Due to the vast applications of the heat and mass transfer over a vertical channel in geophysics and engineering, a lot of authors have studied and published about this subject. Considering the chemical reaction and radiation effects, the common applications that can be found are the combustion of fossil fuels, atmospheric reentry with suborbital velocities, plasma wind tunnels, electric spacecraft propulsion, hypersonic flight through planetary atmosphere photo-dissociation, and photo ionization. Articles have been published based on the study of heat generation or absorption, chemical reaction, and radiation effects. Studies have been done on the individual or collective effects. For instance,
Muthucumaraswamy and Ganesan [5] studied numerically natural convection on a moving isothermal vertical plate with chemical reaction. In their study, they have shown that velocity increases during generative reaction and decreases in destructive reaction. Vajravelu and Hadjinicolaou [6] studied the heat transfer in viscous fluid over a stretching sheet with viscous dissipation and internal heat generation. Kelson and Desseaux [7] examined the effect of surface conditions on the flow of a micropolar fluid driven by a porous stretching sheet. Takhar et al. [8] have investigated the flow and mass diffusion of chemical species with first-order and higher order reactions over a continuously stretching sheet with the magnetic field effect. Influence of chemical reaction on heat and mass transfer by natural convection from vertical surfaces in porous media considering soret and dufour effects was analyzed by Postelnicu [9]. El-Arabawy [10] analyzed the problem of the effect of suction/injection on the flow of a micropolar fluid past a continuously moving plate in the presence of radiation.

The effect of magnetic field with or without hall and ion-slip effects has been studied by several researchers. On uniformly stretched vertical permeable surface in 
the presence of heat generation/absorption and a chemical reaction, Chamkha [11] studied analytically the magnetic effects. Mahmoud [12] considered thermal radiation effects on MHD flow of a micropolar fluid over a stretching surface with variable thermal conductivity. Chemical reaction and heat and mass transfer on MHD flow over a vertical stretching surface with heat source and thermal stratification effects were examined by Kandasamy et al. [13]. Khedr et al. [14] examined numerically MHD flow of a micropolar fluid past a stretched permeable surface with heat generation or absorption neglecting the hall and ion-slip effects.

The abovementioned studies addressed flows when one or more of the effects of chemical reaction, radiation, heat source, and MHD are absent. The objective of this paper is to analyze hall and ion-slip effects of micropolar fluid along a vertical semi-infinite permeable plate taking into account the slip boundary conditions with the combined effects of chemical reaction, radiation, and heat source with wall suction or injection effects. The governing systems of partial differential equations have been solved numerically by the Keller box method. The effects of the various parameters on the velocity, micrototation, temperature, and concentration field will be investigated.

\section{Mathematical Formulation of Problem}

Let us consider a steady, laminar, incompressible micropolar fluid flowing past a porous surface along a semi-infinite vertical plate in the presence of heat generation or absorption and thermal radiation effect. Further, it is assumed that there exists a first-order homogeneous chemical reaction between the species and the fluid, a magnetic field of a uniform strength $B_{0}$ is applied transversely to the plate, and the magnetic Reynolds number is assumed to be small so that the induced magnetic field is neglected. When the fluid is assumed to be viscous and has constant properties retaining the hall and ion-slip effect, the equation governing the flow is given by

$$
\begin{aligned}
\frac{\partial u}{\partial x}+\frac{\partial v}{\partial y}= & 0 \\
\rho\left\{u \frac{\partial u}{\partial x}+v \frac{\partial u}{\partial y}\right\}= & (\mu+\kappa) \frac{\partial^{2} u}{\partial y^{2}}+\kappa \frac{\partial \omega}{\partial y} \\
& -\frac{\sigma B_{0}^{2}}{\alpha_{e}^{2}+B_{e}^{2}}\left\{B_{e} u+\alpha_{e} w\right\} \\
\rho\left\{u \frac{\partial w}{\partial x}+v \frac{\partial w}{\partial y}\right\}= & (\mu+\kappa) \frac{\partial^{2} w}{\partial y^{2}} \\
-2 \kappa \omega-\kappa \frac{\partial u}{\partial y}+\omega \frac{\partial^{2} \omega}{\partial y^{2}}= & 0,
\end{aligned}
$$

$$
\begin{aligned}
u \frac{\partial T}{\partial x}+v \frac{\partial T}{\partial y}= & \alpha \frac{\partial^{2} T}{\partial y^{2}}+\frac{v}{C_{p}}\left(\frac{\partial u}{\partial y}\right)^{2} \\
& -\frac{1}{C_{p}} \frac{\partial q_{r}}{\partial y} \\
& +\frac{Q}{\rho C_{p}}\left(T-T_{\infty}\right), \\
u \frac{\partial C}{\partial x}+v \frac{\partial C}{\partial y}= & D \frac{\partial^{2} C}{\partial y^{2}}-K_{1}\left(C-C_{\infty}\right),
\end{aligned}
$$

where $K_{1}$ is chemical reaction parameter, $B_{0}$ is magnetic field intensity, $D$ is the effective diffusive coefficient, $\rho$ is density, $u$ and $w$ are fluid velocities, $\omega$ is microrotation component, $T$ is temperature, $C$ is concentration, $\mu$ is the dynamic viscosity, $\alpha_{e}=1+B_{e} B_{i}$ is hall parameter, $B_{e}$ is ion-slip parameter, $\alpha$ is the fluid thermal diffusivity, $\sigma$ is fluid electrical conductivity, $Q$ is dimensional heat generation $(>0)$ or absorption $(<0)$ coefficient, and $q_{r}$ is the radiative heat flux.

The boundary conditions are as follows:

$$
\begin{aligned}
& u=u_{w}+L \frac{\partial u}{\partial y}, \\
& v=0 \text {, } \\
& w=0 \text {, } \\
& \varpi=-n \frac{\partial u}{\partial y}, \\
& T=T_{w}, \\
& C=C-w \\
& \text { at } y=0 \text {, } \\
& u \longrightarrow 0 \text {, } \\
& w \longrightarrow 0 \text {, } \\
& \omega \longrightarrow 0 \text {, } \\
& T=T_{\infty}, \\
& C=C_{\infty},
\end{aligned}
$$

$$
\text { as } y \longrightarrow \infty \text {, }
$$

where $L$ is the proportionality constant of the velocity. For microrotation boundary condition, $n=0$ corresponds to no slip, the concentrated particle where the microelements close to the plate surface are unable to rotate. And the case $n=$ $1 / 2$ represents the fact that antisymmetric part of the stress is zero on the surface and weak concentration. The case $n=1$ represents turbulent boundary layer flow.

In (5), the radiative heat flux under Rosseland approximation is given by

$$
q_{r}=-\frac{\sigma^{*}}{3 k^{*}} \frac{\partial T^{4}}{\partial y},
$$

where $\sigma^{*}$ is Stephan-Boltzmann constant and $k^{*}$ is mean absorption coefficient. If the temperature differences within 
the flow are sufficiently small, $T^{4}$ may be expanded by Taylor series. Hence, expanding $T^{4}$ about $T_{\infty}$ and neglecting higher order terms, we get

$$
T^{4} \cong T_{\infty}^{4}+4\left(T-T_{\infty}\right) T_{\infty}^{3}=4 T_{\infty}^{3} T-3 T_{\infty}^{3} .
$$

Introduce the nondimensional variables through

$$
\begin{aligned}
\psi & =2 v x U_{0} f(\eta), \\
u & =\frac{\partial \psi}{\partial y}=U_{0} f^{\prime}(\eta), \\
v & =-\frac{\partial \psi}{\partial x}=-\sqrt{\frac{U_{0} v}{2 x}}\left(f(\eta)-\eta f^{\prime}(\eta)\right), \\
\eta & =y \sqrt{\frac{U_{0}}{2 v x}}, \\
w & =U_{0} h(\eta), \\
\varpi & =\sqrt{\frac{U_{0}^{3}}{2 v x}} g(\eta), \\
\theta(\eta) & =\frac{T-T_{\infty}}{T_{w}-T_{\infty}}, \\
\phi(\eta) & =\frac{C-C_{\infty}}{C_{w}-C_{\infty}} .
\end{aligned}
$$

Substituting (8)-(10) into (1)-(6), we get the following nondimensional equations:

$$
\begin{aligned}
f^{\prime \prime \prime}+f f^{\prime}+N_{1} g^{\prime}-\frac{M^{2}}{\alpha_{e}^{2}+B_{e}^{2}}\left(\alpha_{e} f^{\prime}+B_{e} h\right) & =0, \\
h^{\prime \prime}+\frac{1}{2} h^{\prime} f+\frac{M^{2}}{\alpha_{e}^{2}+B_{e}^{2}}\left(B_{e} f^{\prime}-\alpha_{e} h\right) & =0, \\
\lambda g^{\prime \prime}-2\left(2 g+f^{\prime \prime}\right) & =0, \\
\frac{3 \mathrm{Ra}+4}{3 \mathrm{PrRa}} \theta^{\prime \prime}+f \theta^{\prime}+A \theta+E_{c}\left(f^{\prime \prime}\right)^{2} & =0, \\
\frac{1}{S_{c}} \phi^{\prime \prime}+f \phi^{\prime}-K \phi & =0,
\end{aligned}
$$

where primes denote differentiation with respect to the variable $\eta, N_{1}=\kappa / \rho v$ is coupling number, $A=2 Q / C_{p} \rho U_{0}$ is internal heat generation/absorption parameter, $E_{c}=$ $U_{0}^{2} / c_{p}\left(T_{w}-T_{\infty}\right)$ is the Eckert number, $\operatorname{Pr}=\nu C_{p} / \alpha$ is the Prandtl number, $M=\sqrt{2 \sigma B_{0}^{2} / \rho U_{0}}$ is Hartmann number, $\Gamma=$ $\gamma U_{0} / \kappa \nu$ is microrotation parameter, and $\mathrm{Ra}=k k^{*} / 4 \sigma^{*} T_{\infty}^{3}$ is radiation parameter.
The corresponding boundary conditions in dimensionless form are as follows:

$$
\begin{aligned}
f(0) & =S_{0}, \\
f^{\prime}(0) & =1+\varepsilon f^{\prime \prime}(0), \\
h(0) & =0, \\
g(0) & =-n f^{\prime \prime}(0), \\
\theta(0) & =1, \\
\phi(0) & =1, \\
\eta & \longrightarrow \infty \\
f^{\prime} & \longrightarrow 0, \\
h & \longrightarrow 0, \\
g & \longrightarrow 0, \\
\theta & \longrightarrow 0, \\
\phi & \longrightarrow 0,
\end{aligned}
$$

where $\varepsilon$ is slip parameter and $S_{0}=-V_{0} \sqrt{\nu U_{0} / 2 x}$ is suction/ injection velocity.

The shearing stress component at the plate can be calculated in nondimensional form:

$$
C_{f}=(\mu+\kappa) \frac{(\partial u / \partial y)_{y=0}}{(1 / 2) \rho U_{0}^{2}}=-2 \operatorname{Re}_{x}^{1 / 2} f^{\prime \prime}(0)
$$

The local mass flux and the local Sherwood number are, respectively, given by

$$
\begin{aligned}
\mathrm{Nu}_{x} & =\frac{-x(\partial T / \partial y)_{y=0}}{T_{w}-T_{\infty}}=-2 \operatorname{Re}_{x}^{1 / 2} \theta^{\prime}(0), \\
\mathrm{Sh}_{x} & =\frac{-x(\partial C / \partial y)_{y=0}}{C_{w}-T_{\infty}}=-2 \operatorname{Re}_{x}^{1 / 2} \phi^{\prime}(0),
\end{aligned}
$$

where $\operatorname{Re}_{x}=U_{0} x / v$ is the Reynolds number.

\section{Numerical Scheme}

The numerical scheme to solve (11)-(16) is outlined based on Keller [15] as follows: (11)-(15) are written as a firstorder system of equation. For this, we define new variables $U, V, P, Q, R$, and $S$ as

$$
\begin{aligned}
& f^{\prime}=U, \\
& u^{\prime}=V, \\
& h^{\prime}=S,
\end{aligned}
$$




$$
\begin{aligned}
g^{\prime} & =P, \\
\theta^{\prime} & =Q, \\
\phi^{\prime} & =R, \\
V^{\prime}+f V-n_{1} P-\frac{M^{2}}{\alpha_{e}^{2}+B_{e}^{2}}\left(\alpha_{e} U+B_{e} h\right) & =0, \\
h^{\prime \prime}+f S+\frac{M^{2}}{\alpha_{e}^{2}+B_{e}^{2}}\left(B_{e} U-\alpha_{e} h\right) & =0, \\
\lambda P^{\prime}-2(2 g+V) & =0, \\
\frac{3 \operatorname{Ra}+4}{3 \operatorname{RaPr} Q^{\prime \prime}+f Q+A \theta+E_{c} V^{2}} & =0, \\
\frac{1}{S_{c}} R^{\prime} f-K \phi & =0 .
\end{aligned}
$$

The boundary condition becomes

$$
\begin{aligned}
& \eta=0, \\
& f=0, \\
& U=0, \\
& h=0, \\
& g=0, \\
& \theta=1, \\
& \phi=1, \\
& U \longrightarrow 0, \\
& h \longrightarrow 0, \\
& g \longrightarrow 0, \\
& \theta \longrightarrow 0, \\
& \phi \longrightarrow 0 .
\end{aligned}
$$

We write the difference equation:

$$
\begin{aligned}
\eta_{0} & =0, \\
\eta_{j} & =\eta_{j-1}+\xi_{j}, \quad j=1,2,3, \ldots, J, \\
\eta_{J} & =\eta_{\infty}, \\
\eta_{j-1 / 2} & =\frac{1}{2}\left(\eta_{j}+\eta_{j-1}\right), \\
()_{j-1 / 2} & =\frac{1}{2}\left(()_{j}+()_{j-1}\right),
\end{aligned}
$$

where $\xi_{j}$ is $\Delta \eta$ spacing. Therefore,

$$
\begin{aligned}
& \xi_{j}^{-1}\left(f_{j}-f_{j-1}\right)=U_{j-1 / 2}, \\
& \xi_{j}^{-1}\left(U_{j}-U_{j-1}\right)=V_{j-1 / 2}, \\
& \xi_{j}^{-1}\left(g_{j}-g_{j-1}\right)=P_{j-1 / 2}, \\
& \xi_{j}^{-1}\left(\theta_{j}-\theta_{j-1}\right)=Q_{j-1 / 2} \text {, } \\
& \xi_{j}^{-1}\left(\phi_{j}-\phi_{j-1}\right)=R_{j-1 / 2} \text {, } \\
& \left(V_{j}-V_{j-1}\right)+\frac{\xi_{j}}{4}\left(f_{j}+f_{j-1}\right)\left(V_{j}+V_{j-1}\right) \\
& +N_{1} \frac{\xi_{j}}{2}\left(P_{j}+P_{j-1}\right) \\
& -\frac{\xi_{j} M^{2}}{2\left(\alpha_{e}^{2}+B_{e}^{2}\right)}\left(\alpha_{e}\left(U_{j}+U_{j-1}\right)+B_{e}\left(h_{j}+h_{j-1}\right)\right) \text {, } \\
& \left(S_{j}-S_{j-1}\right)+\frac{\xi_{j}}{4}\left(f_{j}+f_{j-1}\right)\left(S_{j}+S_{j-1}\right) \\
& +\frac{\xi_{j} M^{2}}{2\left(\alpha_{e}^{2}+B_{e}^{2}\right)}\left(B_{e}\left(h_{j}+h_{j-1}\right)-\alpha_{e}\left(E_{j}+E_{j-1}\right)\right), \\
& \lambda\left(P_{j}-P_{j-1}\right)-2 \xi\left(V_{j}+V_{j-1}+2\left(g_{j}+g_{j-1}\right)\right)=0 \text {, } \\
& \frac{3 \mathrm{Ra}+4}{3 \operatorname{RaPr}}\left(Q_{j}-Q_{j-1}\right)+\frac{\xi_{j}}{4}\left(f_{j}+f_{j-1}\right)\left(Q_{j}+Q_{j-1}\right) \\
& +A \frac{\xi_{j}}{2}\left(\theta_{j}+\theta_{j-1}\right)+\frac{\xi_{j}}{4}\left(f_{j}+f_{j-1}\right)^{2}=0, \\
& \frac{1}{S_{c}}\left(S_{j}-S_{j-1}\right)+\frac{\xi_{j}}{4}\left(f_{j}+f_{j-1}\right)\left(R_{j}+R_{j-1}\right) \\
& -\frac{\xi_{j}}{2}\left(\phi_{j}+\phi_{j-1}\right)=0 \text {. }
\end{aligned}
$$

Linearizing the resulting system of equations by Newton method, we will get a block tridiagonal structured matrix and then solve the system using Keller box method. This method has been proven to be adequate and give accurate results for boundary layer equations. The step size $\Delta \eta=0.01$ is chosen after testing with different step sizes. The calculations are repeated until some convergence criterion is satisfied and the calculations were stopped when $\delta f_{0}^{\prime \prime} \leq 10^{-8}, \delta h_{0}^{\prime} \leq 10^{-8}$, $\delta g_{0}^{\prime} \leq 10^{-8}, \delta \theta_{0}^{\prime} \leq 10^{-8}$, and $\delta \phi_{0}^{\prime} \leq 10^{-8}$. In the present study, the boundary conditions for $\eta$ at $\infty$ are replaced by a sufficiently large value of $\eta$ where the velocity, microrotation, temperature, and concentration profiles approach zero. After some trials, we imposed a maximal value of $\eta$ at $\infty$ of 10 .

\section{Results and Discussion}

Computations have been performed using the following parameters: $S_{c}=0.2, \operatorname{Pr}=0.72, \lambda=2, E_{c}=0.02$, Ra very 
TABLE 1: A comparison of values of $\operatorname{Pr}$ when $S_{0}=0, E_{c}=0.02, \lambda=2$, $A=0, \mathrm{Ra}=1000, N_{1}=0.2$, and $K=0$.

\begin{tabular}{lcc}
\hline $\operatorname{Pr}$ & El-Arabawy [10] & Present \\
\hline 0.733 & 0.501327 & 0.50138 \\
7 & 1.931150 & 1.93117 \\
10 & 2.33700 & 2.33714 \\
20.0 & 3.360750 & 3.36076 \\
\hline
\end{tabular}

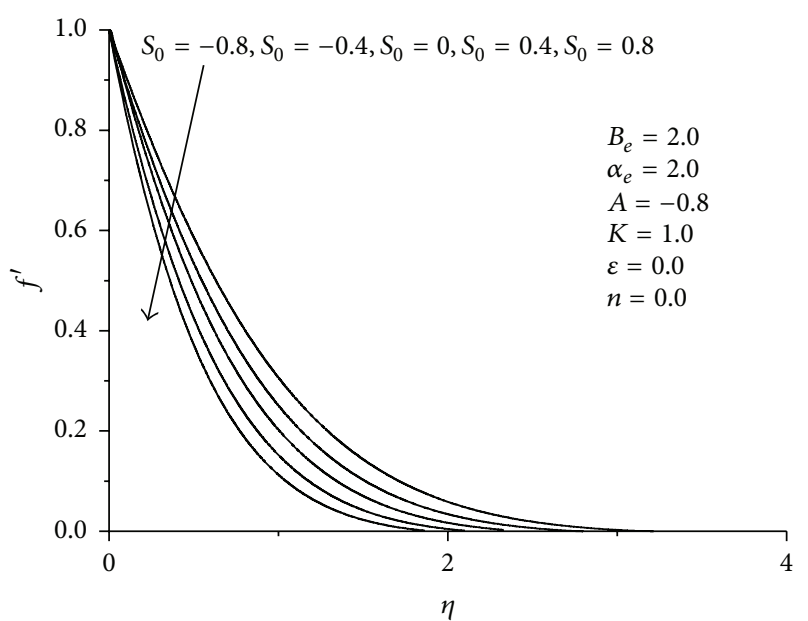

Figure 1: The effect of suction/injection on $f^{\prime}$.

large number, and $N_{1}=0.5$, which represents the presence of microelements; the fluid is micropolar (in (2), when $\kappa \rightarrow 0$ and when $N_{1} \rightarrow 0$ in (11), equations (11) and (13) decouple and the fluid behaves as Newtonian). To validate the code, results are compared with those of El-Arabawy [10] and it was found that they are in good agreement as shown in Table 1.

The effects of the suction/injection parameter on velocities, microrotation, temperature, and concentration are presented in Figures 1-5. It is observed that injecting a fluid at the plate $\left(S_{0}<0\right)$ increases all the velocities, microrotation, temperature, and concentrations. On the other hand, the opposite is observed on all velocities, microrotation, temperature, and concentrations in the case of suction $\left(S_{0}>0\right)$. Similar trend is observed on the boundary layer thicknesses.

Imposition of a magnetic field to an electrically conducting fluid creates a drag like force called the Lorentz force. As it is known, this force has the tendency to slow down the flow. The effect of the hall parameter $\alpha_{e}$ on the velocity profiles studied is shown in Figure 6. Figure 6 shows that velocity increases with increasing $\alpha_{e}$ and the effective conductivity decreases with increasing $\alpha_{e}$ which reduces the magnetic damping force on velocities. In general, increasing the hall and ion-slip parameters increases primary and secondary velocities as seen in Figures 6 and 7. When $\alpha_{2}=0$, it is seen from Figure 7 that velocity component $h$ is zero. The secondary velocity profiles $h$ plotted in Figure 7 reveal that, increasing the values of the hall parameter $\alpha_{e}$, a sharp rise in the velocity profile is observed near the plate. The effect of hall parameter on microrotation depicted in Figure 8 shows similar effect as the velocity component $h$ is shown. The effect

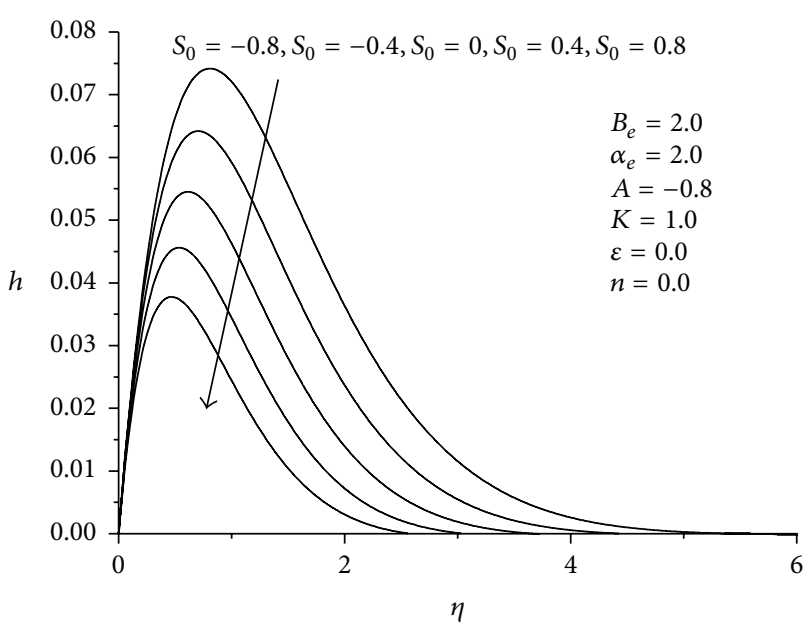

FIgURE 2: The effect of suction/injection on $h$.

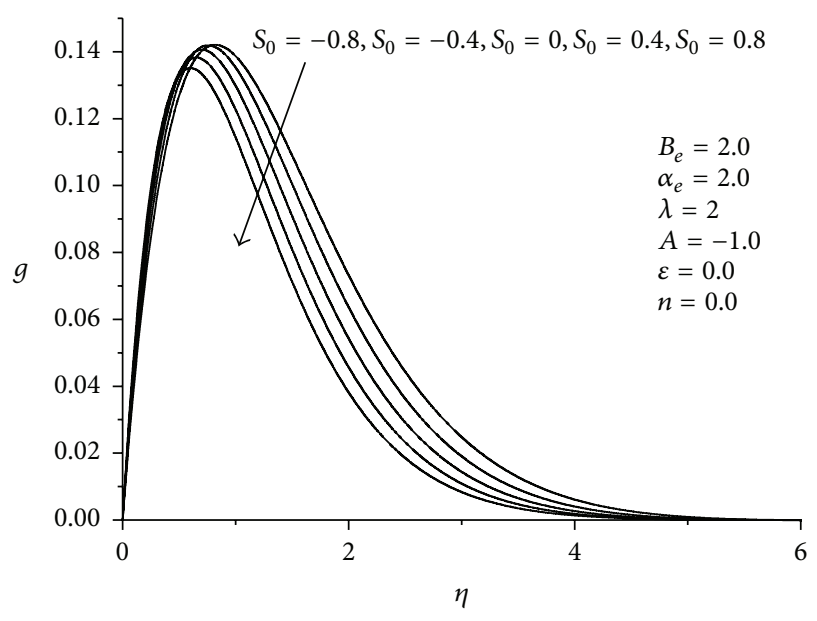

Figure 3: The effect of suction/injection on $g$.

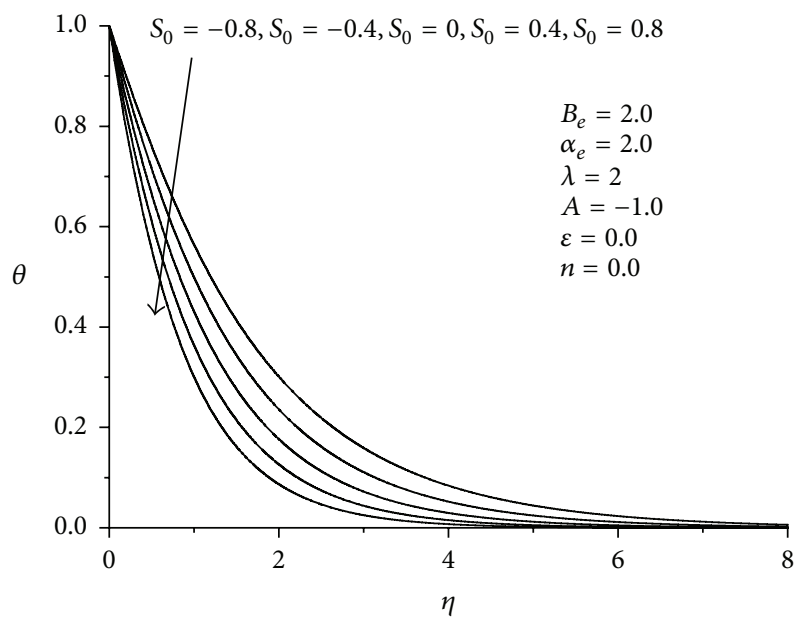

FIGURE 4: The effect of suction/injection on $\theta$. 


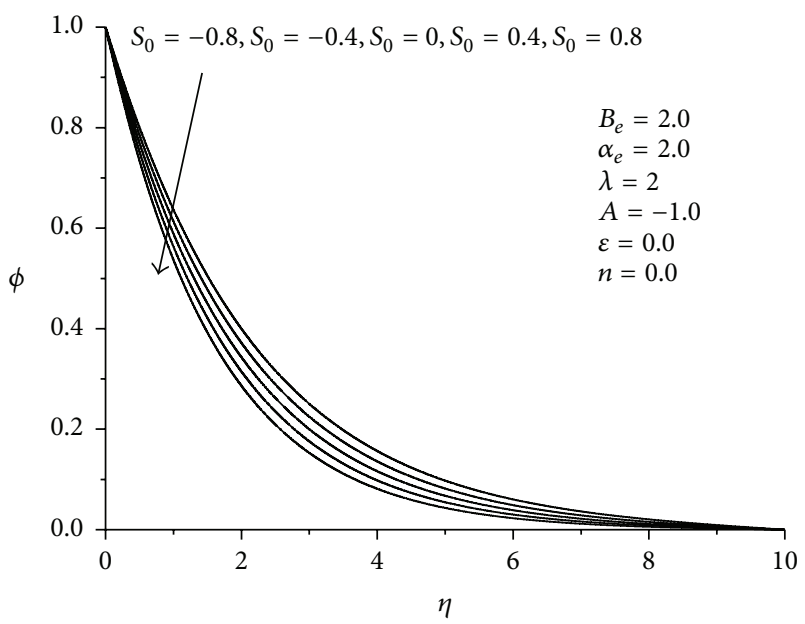

FIgURE 5: The effect of suction/injection on $\phi$.

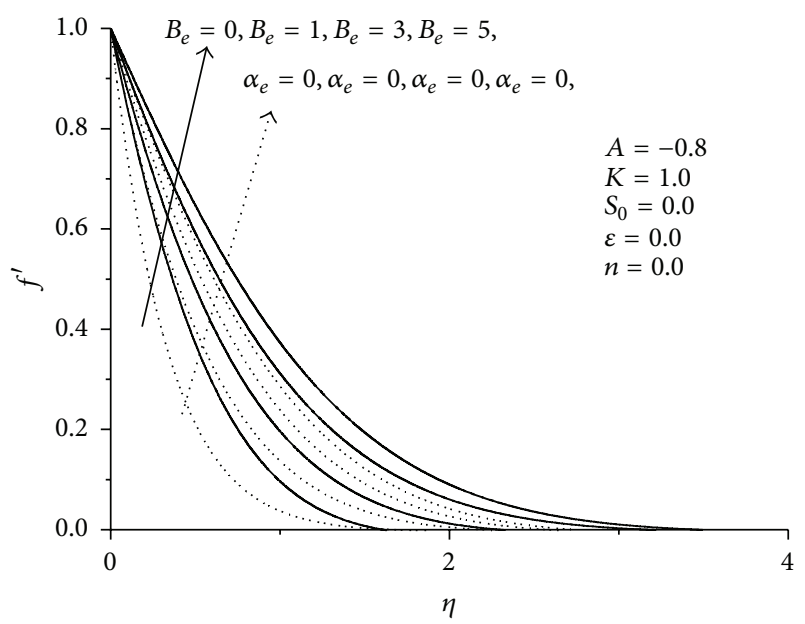

Figure 6: The effect of $B_{e}$ and $\alpha_{e}$ on $f^{\prime}$.

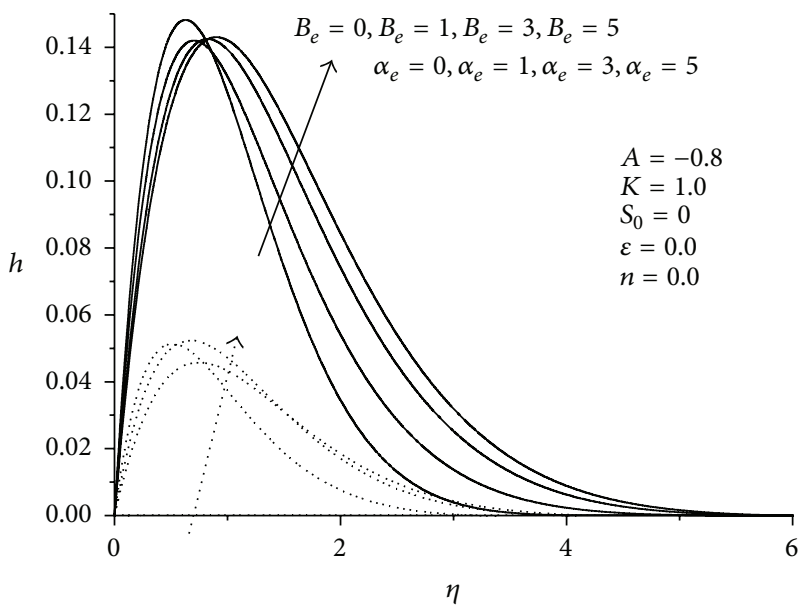

FIgURE 7: The effect of $B_{e}$ and $\alpha_{e}$ on $h$.

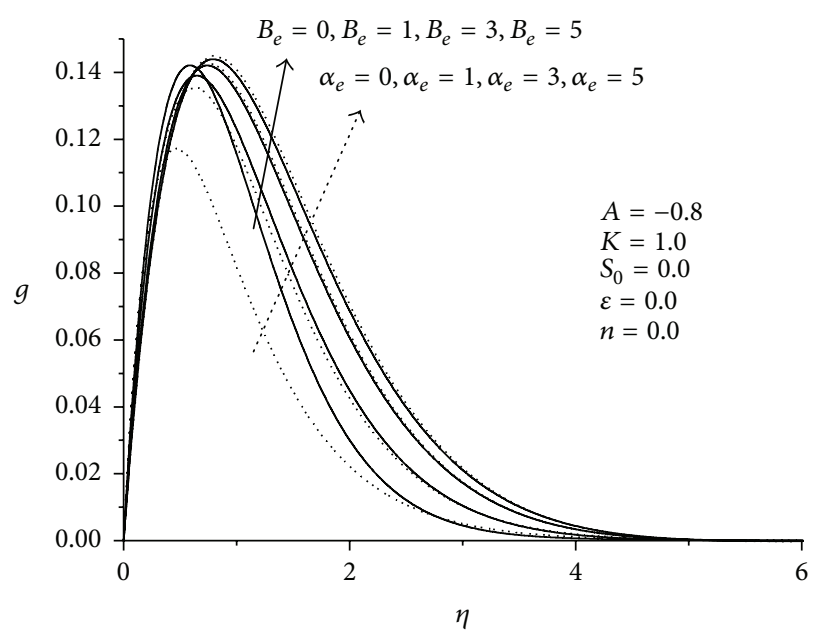

Figure 8: The effect of $B_{e}$ and $\alpha_{e}$ on $g$.

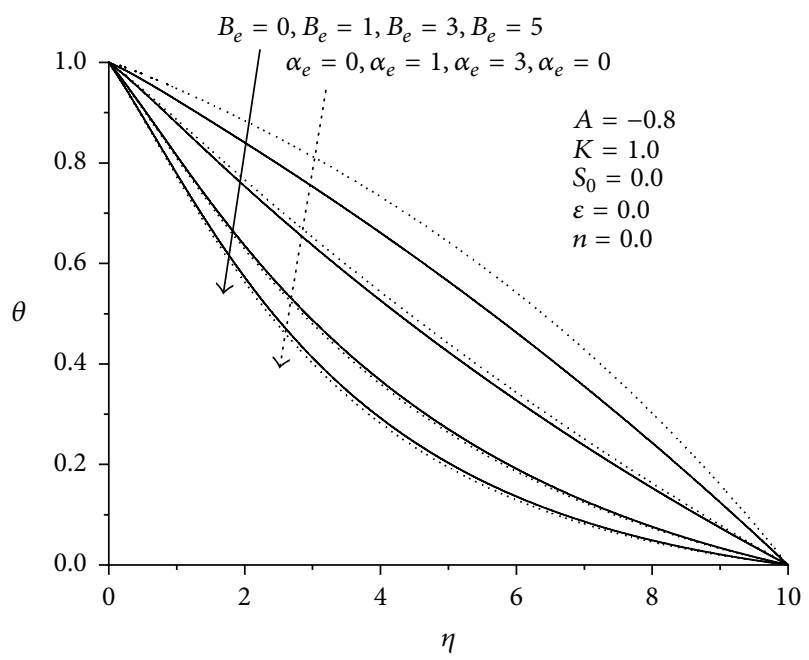

Figure 9: The effect of $B_{e}$ and $\alpha_{e}$ on $\theta$.

of hall and ion-slip however shows a reverse effect on the temperature and concentration as it is depicted in Figures 9 and 10 , respectively.

The effect of the chemical reaction parameter $K$ on the dimensionless concentration is shown in Figure 11. The chemical reaction parameter has a significant effect on the concentration distribution. Increasing the chemical reaction parameter decreases the concentration and the concentration boundary layer thickness.

Our study focused on the case $E_{c}=0.02$, which corresponds to plate cooling, that is, loss of heat from the plate to the fluid. The presence of heat absorption decreases in the thermal state of the fluid. Hence, from Figure 12, it is observed that the fluid temperature is noticeably enhanced with an increased $A$ which also shows the increase in the thermal boundary layer thickness.

The effects of the slip parameter $\varepsilon$ on velocity $f^{\prime}$ are shown in Figure 13. Increasing the sip parameter decreases the velocity, showing that the skin friction decreases at the surface. Figure 14 shows the nondimensional microrotation 


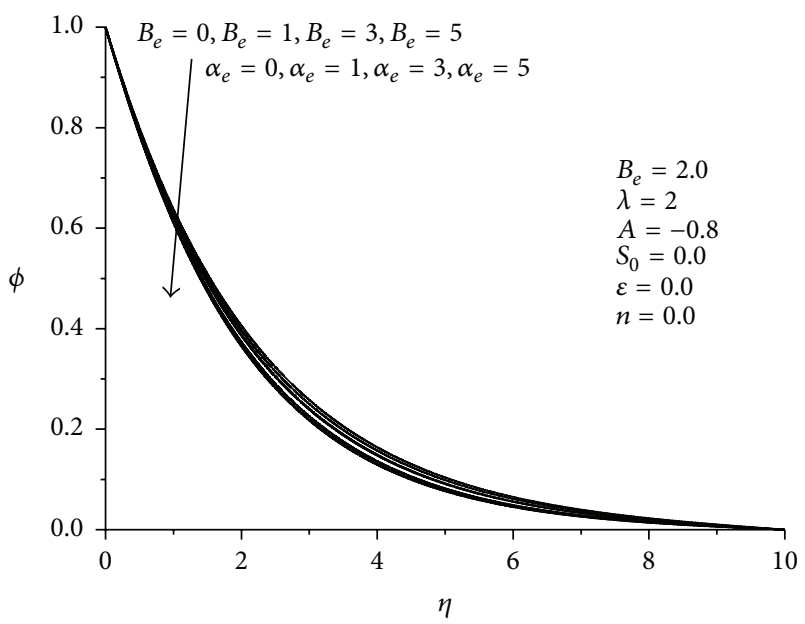

FIGURE 10: The effect of $B_{e}$ and $\alpha_{e}$ on $\phi$.

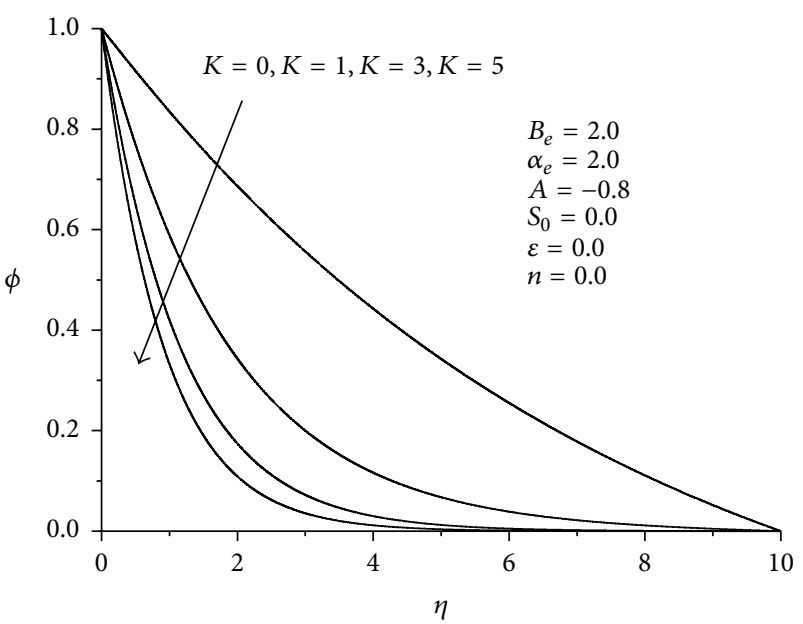

Figure 11: The effect of $K$ on $\phi$.

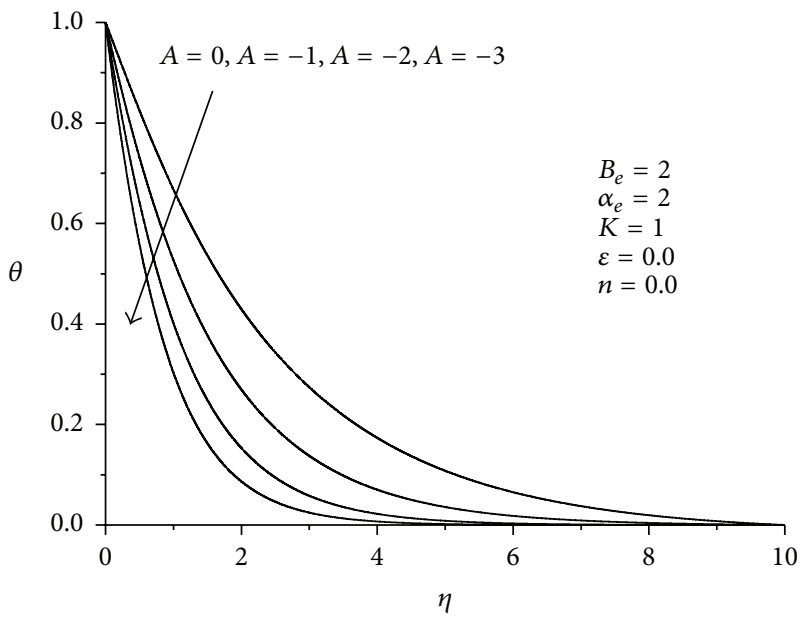

Figure 12: The effect of $A$ on $\theta$.

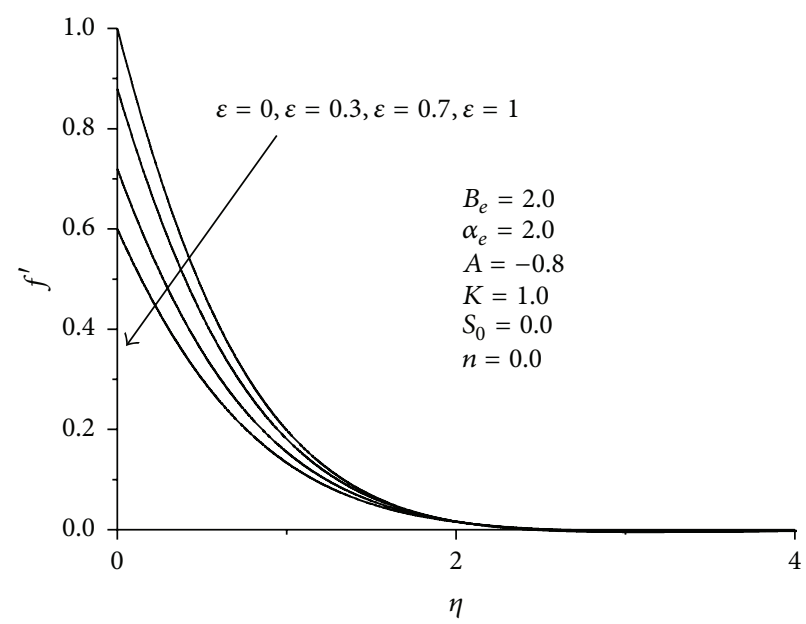

Figure 13: The effect of $\varepsilon$ on $f^{\prime}$.

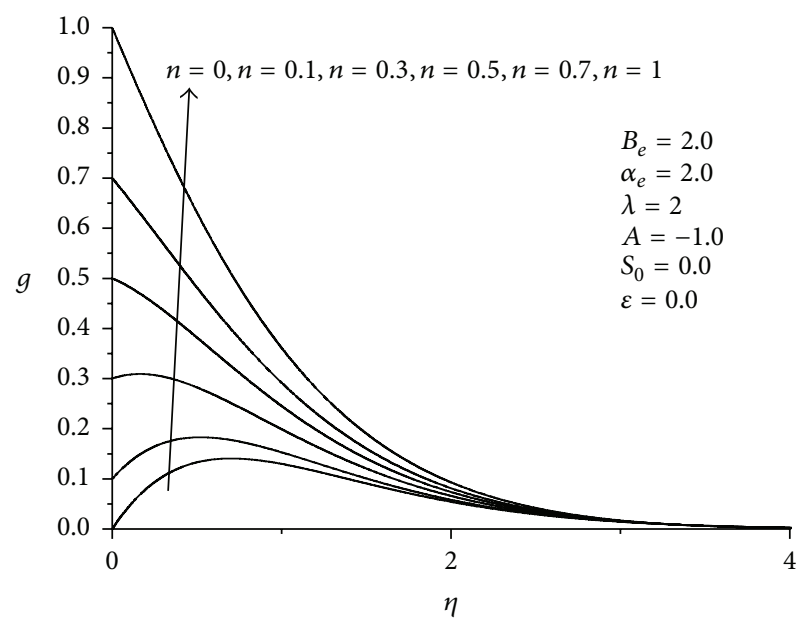

FIGURE 14: The effect of $n$ on $g$.

increases with increase in $n$. It is revealed that microrotation close to the boundary is unable to rotate for the case $n=0$.

The boundary layer produces a drag on the plate due to the viscous stresses, which are developed at the wall, skin friction. The quantity of heat exchanged between the body and the fluid is given by the temperature gradient $\mathrm{Nu}$ (Nusselt number) and the rate of mass transfer Sh (Sherwood number) presented in Tables 2-7 for different values of the parameters. Increasing the suction/injection parameter increases all the skin friction, Nusselt number, and Sherwood numbers. Table 3 shows the effect of the ion-slip parameter. As the ionslip parameter increases, the Nusselt number and Sherwood numbers increase. Table 4 shows similar effects for the hall parameter. The effect of the heat absorption parameter is shown in Table 5. It is observed that the Nusselt number decreases when the absorption parameter increases; however, there is no effect on the skin friction and Sherwood numbers as the equations are decoupled. The slip effect presented in Table 6 shows that as the slip parameter increases skinfriction, Nusselt number, and Sherwood numbers decrease. 
TABLE 2: The effect of suction/injection on skin friction and heat and mass transfer coefficients.

\begin{tabular}{lccc}
\hline$S_{0}$ & $f^{\prime \prime}(0)$ & $\theta^{\prime}(0)$ & $\phi^{\prime}(0)$ \\
\hline-1 & 0.86861 & 0.46342 & 0.07382 \\
-0.5 & 1.06557 & 0.59918 & 0.11458 \\
0 & 1.30799 & 0.77337 & 0.16943 \\
0.5 & 1.59560 & 0.98546 & 0.23824 \\
1 & 1.92459 & 1.23034 & 0.31910 \\
\hline
\end{tabular}

TABLE 3: The effect of $B_{e}$ on skin friction and heat and mass transfer coefficients.

\begin{tabular}{lccc}
\hline$B_{e}$ & $f^{\prime \prime}(0)$ & $\theta^{\prime}(0)$ & $\phi^{\prime}(0)$ \\
\hline 0 & 1.68842 & 0.74200 & 0.14730 \\
1 & 1.52515 & 0.76014 & 0.16020 \\
2 & 1.30799 & 0.77337 & 0.16943 \\
3 & 1.16179 & 0.78229 & 0.17587 \\
4 & 1.06222 & 0.78849 & 0.18054 \\
\hline
\end{tabular}

TABLE 4: The effect of $\alpha_{e}$ on skin friction and heat and mass transfer coefficients.

\begin{tabular}{lccc}
\hline$\alpha_{e}$ & $f^{\prime \prime}(0)$ & $\theta^{\prime}(0)$ & $\phi^{\prime}(0)$ \\
\hline 0 & 2.97849 & 0.71014 & 0.13581 \\
1 & 1.67501 & 0.75506 & 0.15781 \\
2 & 1.30799 & 0.77337 & 0.16943 \\
3 & 1.12814 & 0.78386 & 0.17680 \\
4 & 1.01978 & 0.79066 & 0.18190 \\
\hline
\end{tabular}

TABLE 5: The effect of $A$ on skin friction and heat and mass transfer coefficients.

\begin{tabular}{lccc}
\hline$A$ & $f^{\prime \prime}(0)$ & $\theta^{\prime}(0)$ & $\phi^{\prime}(0)$ \\
\hline 0 & 1.30799 & 0.35464 & 0.16943 \\
-1 & 1.30799 & 0.84147 & 0.16943 \\
-2 & 1.30799 & 1.11637 & 0.16943 \\
-3 & 1.30799 & 1.33259 & 0.16943 \\
-4 & 1.30799 & 1.51709 & 0.16943 \\
\hline
\end{tabular}

TABLE 6: The effect of $\varepsilon$ on skin friction and heat and mass transfer coefficients.

\begin{tabular}{lccc}
\hline$\varepsilon$ & $f^{\prime \prime}(0)$ & $\theta^{\prime}(0)$ & $\phi^{\prime}(0)$ \\
\hline 0 & 0.94209 & 0.51326 & 0.08851 \\
0.2 & 0.85908 & 0.50550 & 0.08394 \\
0.4 & 0.77743 & 0.49771 & 0.07942 \\
0.7 & 0.65752 & 0.48599 & 0.07273 \\
1 & 0.54063 & 0.47425 & 0.06618 \\
\hline
\end{tabular}

Increasing $n$, both $\mathrm{Nu}$ and $\mathrm{Sh}$ decrease whereas the skin friction $C_{f}$ increases as shown in Table 7.

\section{Conclusion}

The steady incompressible chemically reacting micropolar fluid flow along a semi-infinite vertical plate in the presence
TABLE 7: The effect of $n$ on skin friction and heat and mass transfer coefficients.

\begin{tabular}{lccc}
\hline$n$ & $f^{\prime \prime}(0)$ & $\theta^{\prime}(0)$ & $\phi^{\prime}(0)$ \\
\hline 0 & 0.94209 & 0.51326 & 0.08851 \\
0.2 & 1.03079 & 0.50886 & 0.08490 \\
0.4 & 1.11950 & 0.50444 & 0.08132 \\
0.7 & 1.25257 & 0.49777 & 0.07602 \\
1 & 1.38564 & 0.49107 & 0.07081 \\
\hline
\end{tabular}

of heat generation or absorption with heat source under uniform transverse magnetic field has been studied numerically. The effects of hall, ion, chemical reaction, slip, and suction/injection parameters on velocities, microrotation, temperature, and concentration have been investigated. The hall and ion-slip parameters increase the main velocity whereas the slip parameter decreases. The microrotation increases with increase in suction/injection, slip, hall, and ion-slip parameters. Temperature decreases with the increases in hall, ion-slip, and suction/injection parameters whereas it decreases with heat absorption parameters. The chemical reaction profile is highly influenced by the chemical reaction parameter. The skin friction at the wall decreases by increasing the hall, ion-slip, and slip parameters.

\section{Competing Interests}

The authors declare that there are no competing interests regarding the publication of this paper.

\section{References}

[1] A. C. Erigen, "Theory of micropolar fluids," Journal of Mathematics and Mechanics, vol. 16, pp. 1-18, 1966.

[2] A. C. Erigen, “Theory of thermomicropolar fluids," Journal of Mathematical Analysis and Applications, vol. 38, pp. 480-496, 1972.

[3] T. Ariman, M. A. Turk, and N. D. Sylvester, "Microcontinuum fluid mechanics-a review," International Journal of Engineering Science, vol. 11, no. 8, pp. 905-930, 1973.

[4] T. Ariman, M. A. Turk, and N. D. Sylvester, "Applications of microcontinuum fluid mechanics," International Journal of Engineering Science, vol. 12, no. 4, pp. 273-293, 1974.

[5] R. Muthucumaraswamy and P. Ganesan, "Natural convection on a moving isothermal vertical plate with chemical reaction," Journal of Engineering Physics and Thermophysics, vol. 75, no. 1, pp. 113-119, 2002.

[6] K. Vajravelu and A. Hadjinicolaou, "Heat transfer in a viscous fluid over a stretching sheet with viscous dissipation and internal heat generation," International Communications in Heat and Mass Transfer, vol. 20, no. 3, pp. 417-430, 1993.

[7] N. A. Kelson and A. Desseaux, "Effect of surface conditions on flow of a micropolar fluid driven by a porous stretching sheet," International Journal of Engineering Science, vol. 39, no. 16, pp. 1881-1897, 2001.

[8] H. S. Takhar, A. J. Chamkha, and G. Nath, "Flow and mass transfer on a stretching sheet with a magnetic field and chemically reactive species," International Journal of Engineering Science, vol. 38, no. 12, pp. 1303-1314, 2000. 
[9] A. Postelnicu, "Influence of chemical reaction on heat and mass transfer by natural convection from vertical surfaces in porous media considering Soret and Dufour effects," Heat and Mass Transfer, vol. 43, no. 6, pp. 595-602, 2007.

[10] H. A. M. El-Arabawy, "Effect of suction/injection on the flow of a micropolar fluid past a continuously moving plate in the presence of radiation," International Journal of Heat and Mass Transfer, vol. 46, no. 8, pp. 1471-1477, 2003.

[11] A. J. Chamkha, "MHD flow of a uniformly streched vertical permeable surface in the presence of heat generation/absorption and a chemical reaction," International Communications in Heat and Mass Transfer, vol. 30, no. 3, pp. 413-422, 2003.

[12] M. A. A. Mahmoud, "Thermal radiation effects on MHD flow of a micropolar fluid over a stretching surface with variable thermal conductivity," Physica A: Statistical Mechanics and its Applications, vol. 375, no. 2, pp. 401-410, 2007.

[13] R. Kandasamy, K. Periasamy, and K. K. S. Prabhu, "Chemical reaction, heat and mass transfer on MHD flow over a vertical stretching surface with Heat Source and Thermal Stratification Effects," International Journal of Heat and Mass Transfer, vol. 48, no. 21-22, pp. 4557-4561, 2005.

[14] M.-E. M. Khedr, A. J. Chamkha, and M. Bayomi, "MHD flow of a micropolar fluid past a stretched permeable surface with heat generation or absorption," Nonlinear Analysis: Modelling and Control, vol. 14, no. 1, pp. 27-40, 2009.

[15] H. B. Keller, "A new difference method for parabolic problems," in Numerical Methods for Partial Differential Equations, J. Bramble, Ed., pp. 327-350, Academic Press, New York, NY, USA, 1970. 


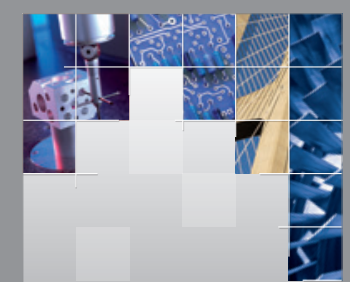

\section{Enfincering}
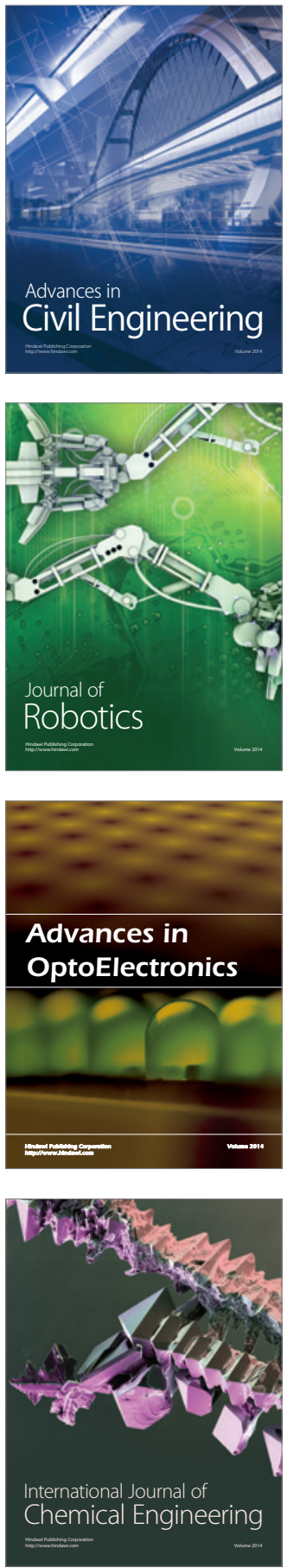

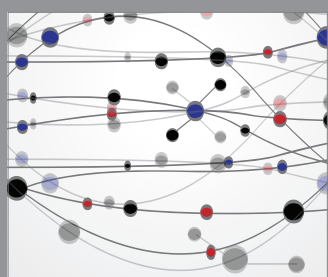

The Scientific World Journal

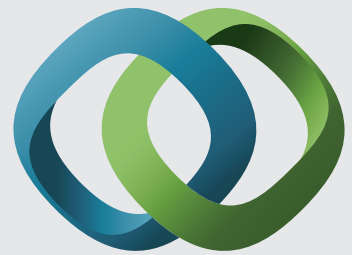

\section{Hindawi}

Submit your manuscripts at

http://www.hindawi.com
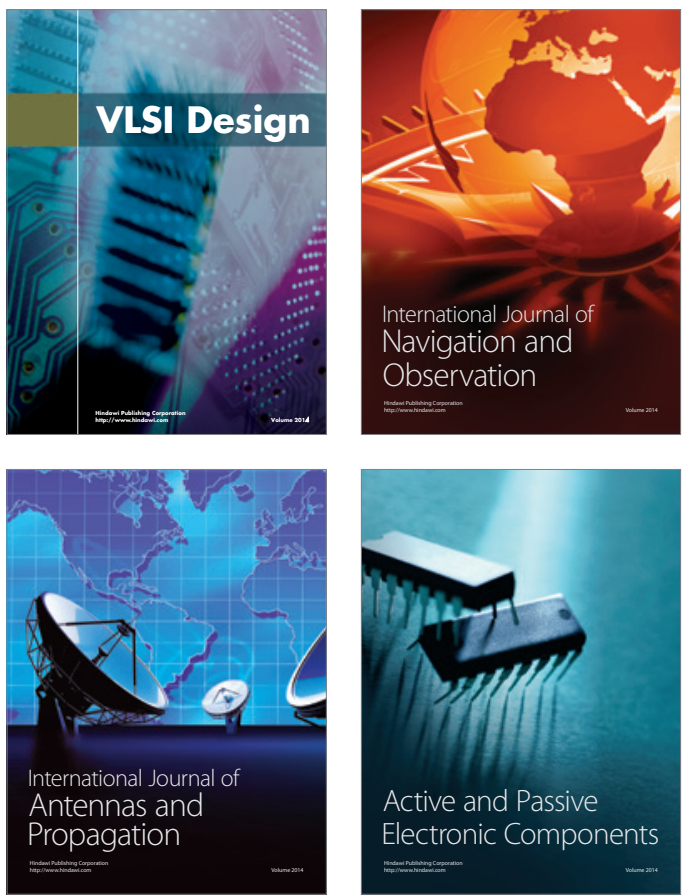
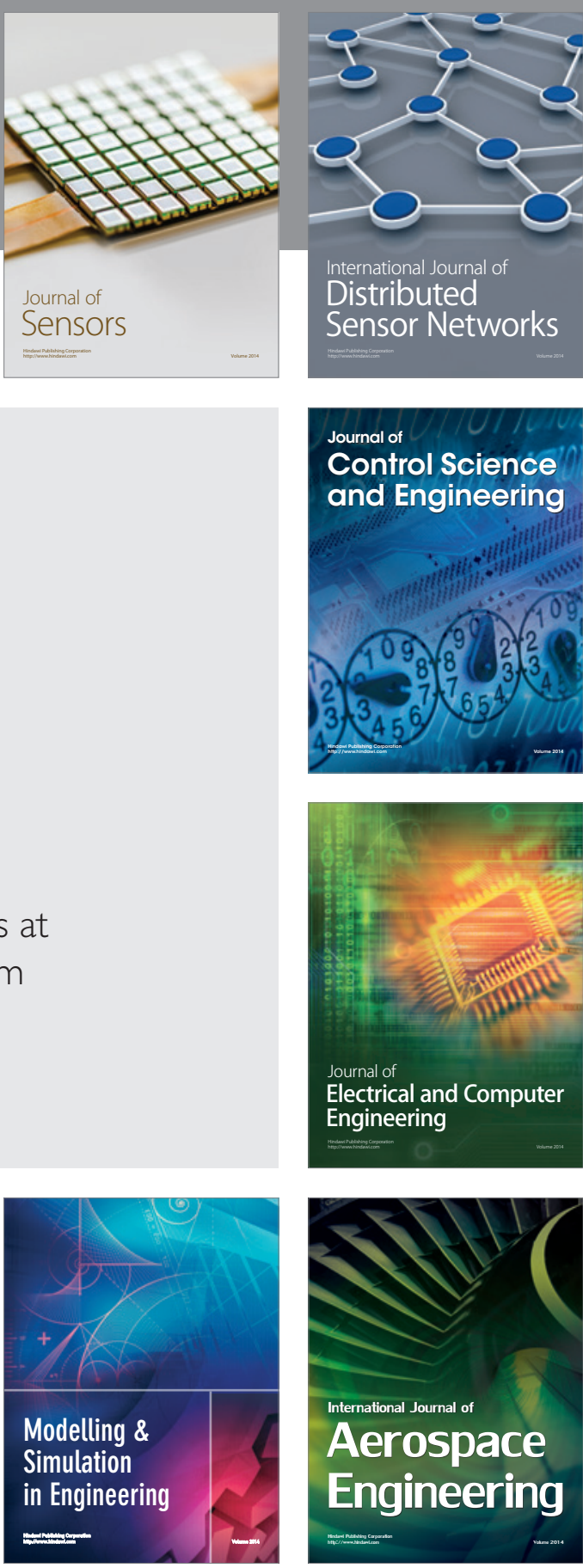

International Journal of

Distributed

Sensor Networks

Journal of

Control Science

and Engineering
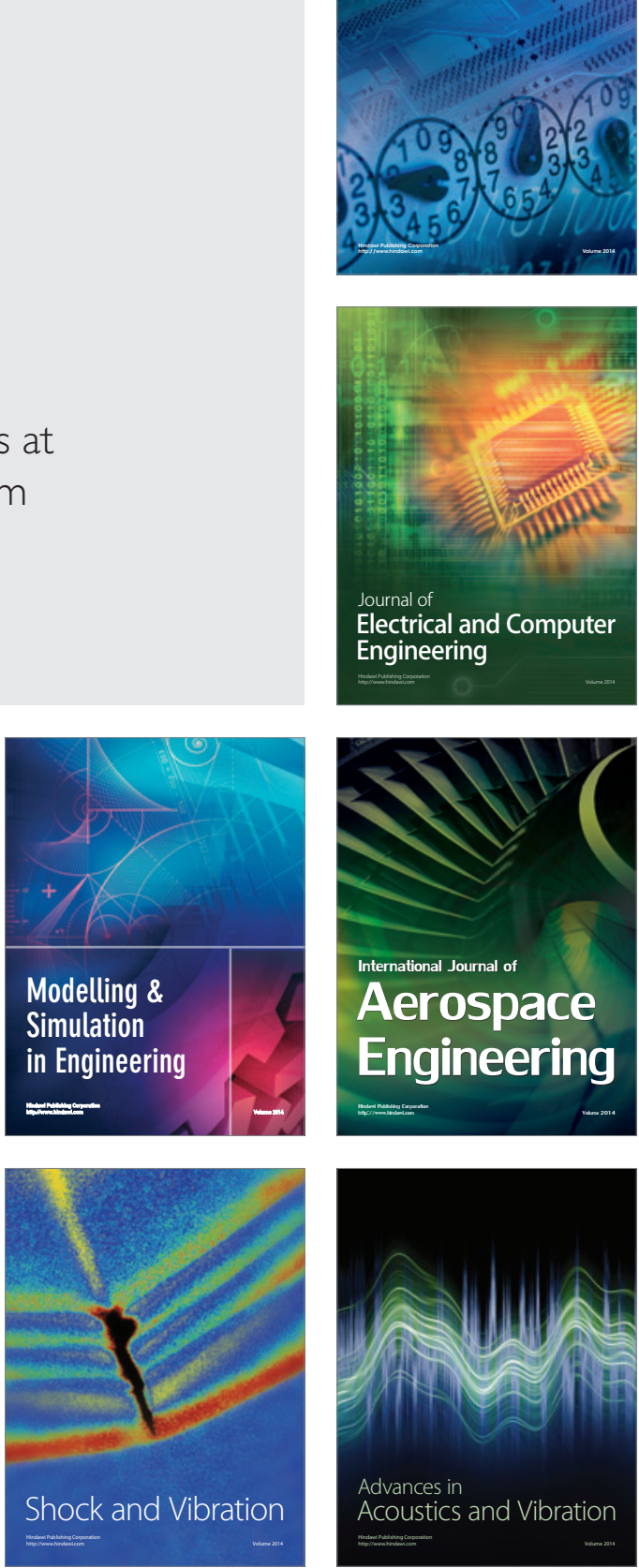